Available online at http://jurnal.stmikroyal.ac.id/index.php/jurteksi

\title{
RANCANG BANGUN APLIKASI EDUCATION MODULE MENGGUNAKAN MACROMEDIA FLASH SEBAGAI ALAT BANTU AJAR MATERI FANTASY UNTUK ANAK PLA YGROUP BERBASIS LOCAL AREA NETWORK
}

\author{
Agus Suryadi \\ Program Studi Sistem Informasi, STMIK Royal Kisaran \\ email: agussuryadi@royal.ac.id
}

\begin{abstract}
Introduce computer technology as a medium of learning the child wisely early on the potential to improve learning ability in children and child develop self-confidence about the future. The reality of child loved the games and television entertainment programs not only viewed negatively, but rather as learning modalities. Provide educational type programs that can be done with a computer as a device supporting a new power of learning media. Children not only learn computer skills, but also utilize the computer as a means or medium for learning. To get optimum benefit Teachers can integrate the use of computers as a medium in the learning process and focus on highorder thingking skill. Fantasy Drafting module aims to develop the potential and effectiveness of learning in early childhood or playgroup, where the module is designed as an education module to read and write the material fauna and flora, coloring and coloring as well. Module proram also implemented into the Local Area Network networking technology to be applied easily and efficiently.
\end{abstract}

Keywords: education module application, tool, fantasy

\begin{abstract}
Abstrak: Mengenalkan teknologi komputer sebagai media pembelajaran kepada anak sejak dini secara bijaksana berpotensi untuk meningkatkan kemampuan belajar pada anak dan mengembangkan rasa percaya diri anak akan masa depannya. Realitas anak sangat menyukai games dan program-program hiburan televisi tidak seharusya hanya dipandang negatif, namun lebih sebagai modalitas belajar. Menyediakan program sejenis yang edukatif bisa dilakukan dengan komputer sebagai perangkat pendukungnya menjadi kekuatan baru media pembelajaran. Anak bukan saja belajar ketrampilan komputer, namun juga memanfaatkan komputer sebagai sarana atau media untuk belajar. Guna mendapatkan manfaat optimal Guru bisa mengintegrasikan penggunaan komputer sebagai media di dalam proses pembelajaran dan fokus kepada high order thingking skill. Perancangan modul fantasy bertujuan untuk mengembangkan potensi dan keefektifan cara belajar pada anak usia dini atau playgroup, dimana modul dirancang sebagai education module dengan materi baca dan tulis fauna serta flora, mewarnai dan juga mewarnai. Modul proram diimplementasikan pula ke dalam teknologi jaringan Local Area Network agar dapat di aplikasikan dengan mudah dan efisien.
\end{abstract}

Kata Kunci : aplikasi education module, alat bantu, fantasy 


\section{PENDAHULUAN}

Prestasi belajar anak-anak di sekolah sering diindikasikan dengan permasalahan belajar dari anak-anak tersebut dalam memahami materi. Indikasi ini dimungkinkan karena faktor belajar anak-anak yang kurang efektif, bahkan anak-anak sendiri tidak merasa termotivasi di dalam mengikuti pembelajaran di kelas playgroup, sehingga menyebabkan anak-anak kurang atau bahkan tidak memahami materi yang bersifat sukar yang di berikan oleh guru tersebut. Kecenderungan pembelajaran yang kurang menarik ini merupakan hal yang wajar di alami oleh guru yang tidak memahami kebutuhan dari anak-anak tersebut baik dalam karakteristik, maupun dalam pengembangan ilmu.

Pembelajaran yang baik dapat ditunjang dari suasana pembelajaran yang kondusif serta hubungan komunikasi antara guru dan anak-anak dapat berjalan dengan baik. Berangkat dari hal tersebut multimedia interaktif dalam kelas dikembangkan atas dasar asumsi bahwa proses komunikasi di dalam pembelajaran akan lebih bermakna (menarik minat anak-anak dan memberikan kemudahan untuk memahami materi karena penyajiannya yang interaktif), jika memanfaatkan berbagai media sebagai sarana penunjang kegiatan pembelajaran.

\section{Modul Pembelajaran Fantasy}

Modul pembelajaran fantasy atau

dalam Bahasa Indonesia fantasi merupakan pola imajinasi pada anak dengan menggunakan otak kanan pada anak sebagai pengembanngan daya kreatifitas dan imajinatif. Fantasy juga merupakan bagian dari ranah psikomotorik yang berhubungan dengan hasil belajar yang pencapaiannya melalui keterampilan manipulasi yang melibatkan nalar fantasy anak tersebut. Ranah psikomotor adalah ranah yang berhubungan aktivitas fisik, dalam hal ini berkreasi dengan menggunakan komputer sebagai alat bantu belajar elektronik pada anak.

\section{Modul Pembelajaran Mewarnai}

Mewarnai adalah kegiatan yang disukai anak-anak khususnya dalam tahap belajar, dengan belajar mewarnai gambar dapat juga melatih otak kanan mereka sehingga dapat membantu menumbuhkan kreatifitas pada anak-anak yang memang dalam tahap perkembangan.

Aktifitas mewarnai merupakan aktifitas yang dapat membantu meningkatkan kinerja otot tangan sekaligus mengembangkan kemampuan motorik anak. Kemampuan tersebut sangat penting dalam perkembangan aktifitasnya kelak, seperti dalam mengetik, mengangkat benda dan aktifitas lainnya dimana dibutuhkan kinerja otot lengan dan tangan dalam prosesnya.

Aktifitas mewarnai dapat melatih konsentrasi anak untuk tetap fokus pada pekerjaan yang dilakukannya meskipun banyak aktifitas lain yang terjadi di sekelilingnya. Seorang anak yang sedang menyelesaikan tugas mewarnai akan fokus pada objek gambar yang sedang diwarnainya, sehingga sekalipun pun di sekelilingnya ribut dengan aktifitas anakanak lain, ia akan tetap fokus menyelesaikan tugas mewarnainya. Kemampuan berkonsentrasi inilah yang kelak berguna bagi anak dalam menyelesaikan soal matematika atau pelajaran lainnya yang membutuhkan konsentrasi tinggi.

\section{Modul Pembelajaran Bernyanyi}

Bernyanyi merupakan suatu bagian yang penting dalam pengembangan diri anak, Ruswandi (2004:13) dalam Asti (2007:32) mengemukakan bahwa bernyanyi bagi anak merupakan kegiatan yang menggunakan instrument suara yang dpat menambah pembendaharaan kata serta wawasan mengenai halhal yang belum ia ketahui. Anak-anak akan banyak belajar kata-kata baru, 
sehingga dpat memperkaya perbendaharaan kata mereka dan lebih terampil dalam mempergunakannya.

\section{Modul Pembelajaran Membaca}

Metode mengajar pada tingkat playgroup membaca sangatlah beragam. Karena begitu beragamnya, lagi-lagi kita akan menemukan perbedaan dasar pemikiran dari metode-metode tersebut, meskipun demikian hal tersebut tidak perlu dipikirkan, kenali saja semua konsep yang ditawarkan dan kenali pula gaya belajar anak-anak. Jika metode dan gaya belajar cocok, hal tersebut dapat lebih mudah memotivasi anak untuk belajar.

Peneliti dalam hal ini mencoba membuat rancangan untuk merangsang stimulasi anak dan mencoba memadukan pembelajaran membaca melalui media pengenalan flora dan fauna pada anakanak, dimana diharapkan dengan aplikasi ini dapat membantu pembelajaran membaca pada anak playgroup, dengan kata lain hal ini juga dapat membantu perangsangan otak kiri, adapun karakteristik otak kanan berhubungan dengan rima, irama, musik, gambar, dan imajinasi. Aktivitas kreatifitas anak juga muncul atas hasil kerja otak kanan.

\section{Modul Pembelajaran Menulis}

Kegiatan menulis, pada dasarnya, merupakan kegiatan yang baik dilakukan oleh anak. Dengan menulis, kreativitas anak dapat ditingkatkan. Dengan menulis, seorang anak ibarat membenamkan diri dalam proses kreatif. Karena ketika ia menulis, itu berarti anak menciptakan sesuatu, yang juga berarti melontarkan pertanyaan-pertanyaan, mengalami keraguan dan kebingungan, sampai akhirnya menemukan pemecahan. Dan ketika proses kreatif tersebut semakin dilatih, anak akan semakin mudah untuk mengalihkan keahliannya kepada bidang lain yang juga membutuhkan solusi kreatif, seperti sekolah maupun kegiatankegiatan lainnya.

Didalam konsep bisnis terpadu, sebuah perusahaan berusaha melakukan integrasi kearah dua sisi: supply dan demand. Kedua arah pengintegrasian ini melahirkan supply chain management dan customer relationship management. Kerja sama yang dijalin antar perusahaan tersebut digolongkan sebagai e-commerce bertipe business-to-business (Indrajit dan Djokopranoto : 162). Business-to-business merupakan tipe kerjasama yang dijalin antar perusahaan dalam mekanisme transaksi jual beli didalam dunia maya, merupakan salah satu tipe dari perdagangan elekronik (e-commerce). (Indrajit \& Djokopranoto:162). Dilihat dari karakteristik hubungan yang ada 5 kalsifikasi B2B yaitu, Sell Side Sites, Distribution Portal, Vertical Excanges, Procument Portals, dan Buy Side Sites.

\section{METODOLOGI}

Metode penelitian yang dilakukan untuk penelitian ini adalah:

1. Pengamatan (Observasi)

Dilakukan dengan cara mengamati sistem dan faktor-faktor yang berpengaruh dalam objek penelitian ini

2. Wawancara

Dilakukan dengan tanya jawab dengan beberapa pihak yang terkait dan berwenang

3. Kepustakaan

Menggunakan buku-buku, penelitian sebelumnya dan jurnal yang berhubungan dengan topik dan masalah dalam penelitian

\section{HASIL DAN PEMBAHASAN}

Desain Secara Umum

Context Diagram 
Context diagram adalah pendefinisian terhadap sistem yang akan dirancang yang bersifat menyeluruh.

Context diagram digunakan untuk memudahkan proses penganalisaan terhadap suatu sistem, adapun context

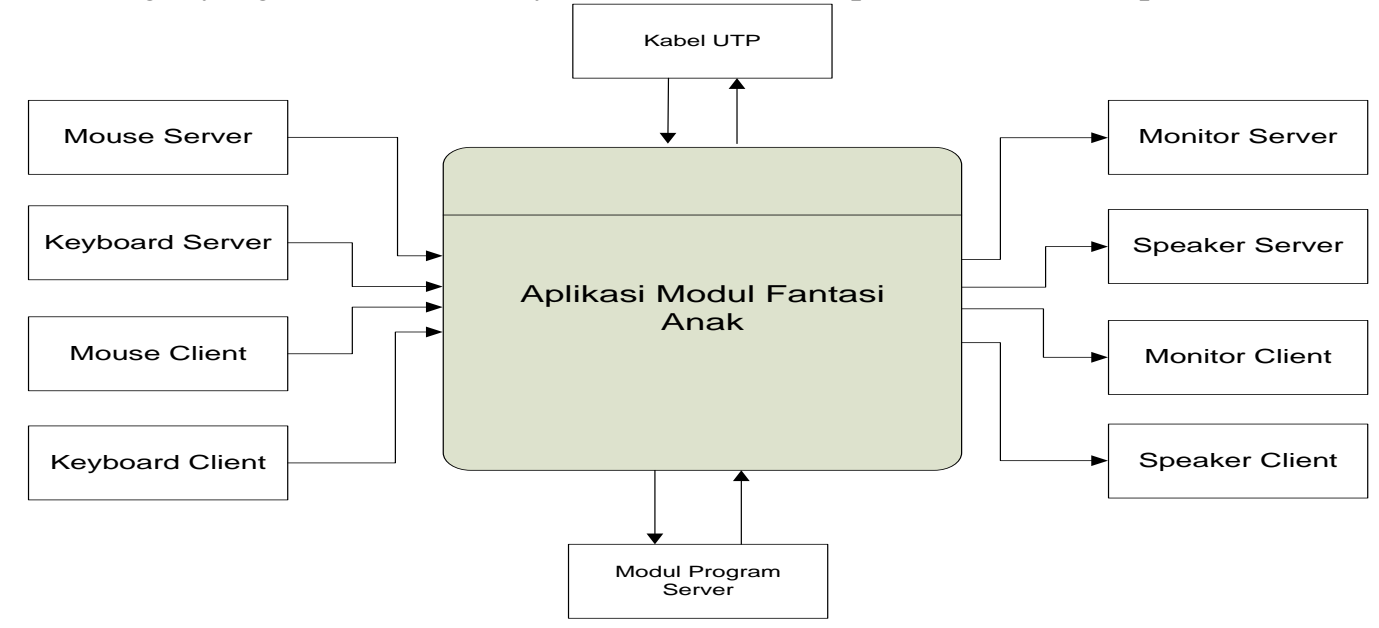

Gambar 1. Context Diagram

diagram yang dimaksud dapat dilihat dalam gambar 1.

\section{Tampilan Pengujian Program Aplikasi}

Program aplikasi yang telah dibuat merupakan perancangan pada modul fantasi, yang dimana di bagi kedalam konten seni dan konten membaca dan menulis. Konten seni berisi tentang mewarnai suatu object dan bernyannyi. Sedangkan konten membaca dan menulis berisi tentang flora dan fauna yang di khususkan untuk anak-anak playgroup, dimana tampilannya sebagai berikut:

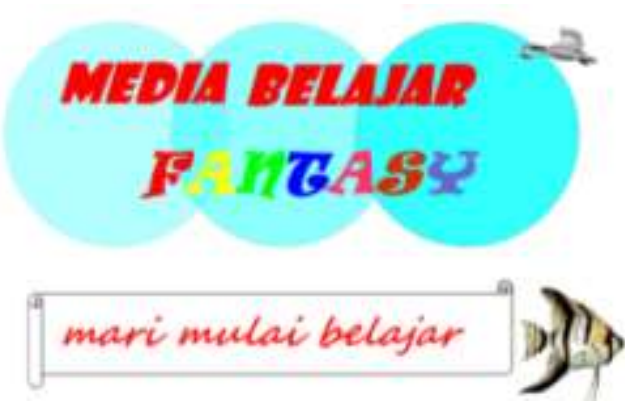

Gambar 2. Tampilan Opening Program Modul Fantasi
Pada halaman menu utama ini terdiri atas tombol materi, option, help, about, dan exit. Sebelum masuk ke materi modul fantasi, terlebih dulu lihat konfigurasi dan beberapa informasi lainnya.

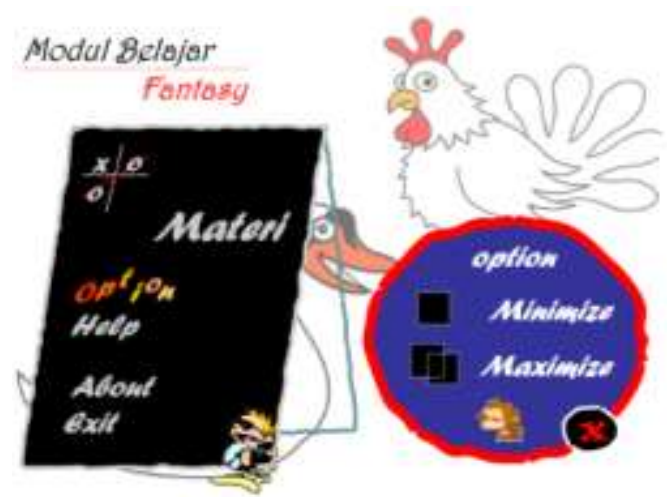

Gambar 3. Tampilan Menu Option

Pada tampilan dibawah ini adalah tampilan dari menu isi materi fantasi yang terdiri dari konten seni, konten membaca dan menulis. Konten seni berupa seni mewarnai dan seni bernyanyi sedangkan konten membaca dan menulis berupa 
membaca dan menulis tentang flora (tumbuh-tumbuhan) dan fauna (hewan).

Tampilan pilihan mewarnai ini terdiri dari objek gambar untuk diwarnai yang telah disediakan yaitu gambar ikan, mobil, rumah, bola dan burung. Halaman mewarnai ini merupakan fitur yang digunakan untuk mewarnai objek gambar yang kita inginkan dengan teknik drag dan drop.

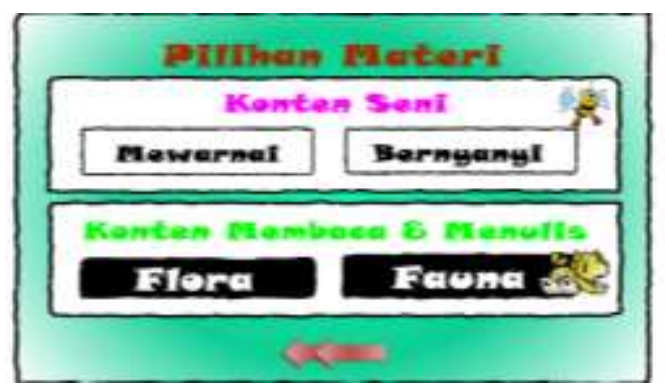

Gambar 4. Tampilan Menu Materi Fantasi

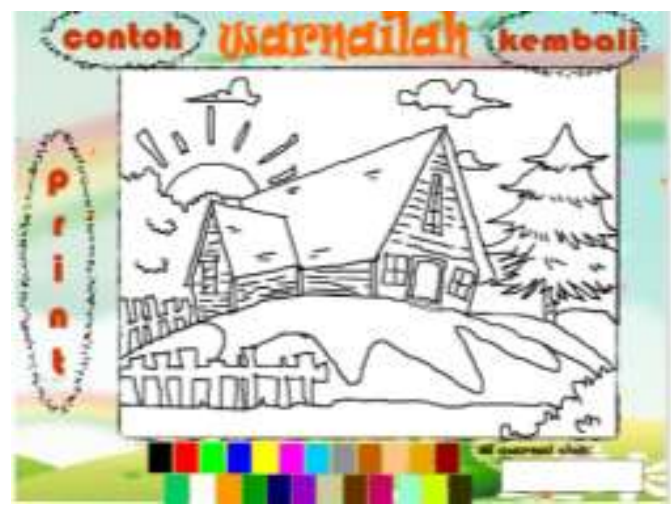

Gambar 5. Tampilan Mewarnai Objek Rumah

Halaman membaca dan menulis flora ini merupakan fitur yang digunakan untuk membaca objek gambar yang kita inginkan dari huruf abjad A sampai Z.

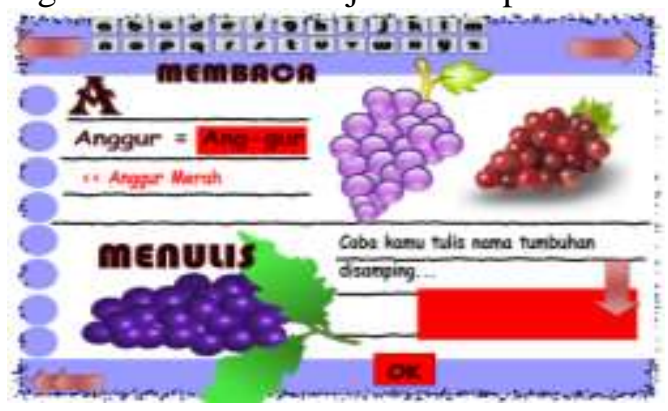

Gambar 6. Tampilan Pilihan

Membacadan Menulis Flora

\section{SIMPULAN}

Dari hasil penelitian dapat disimpulkan:

1. Flash 8 adalah sebuah program yang mampu untuk membuat game, animasi kartun, dan aplikasi multimedia interaktif seperti tutorial fantasy yang terbagi atas materi bernyanyi, mewarnai, membaca dan menulis.

2. Berkas yang dihasilkan dari Macromedia flash 8 mempunyai file extension .swf dan dapat diputar pada media belajar berbasiskan jaringan Local Area Network.

3. Perancangan modul fantasy dapat didesain dan diprogram melalui pemprograman Action Script dengan bantuan simbol berupa button, movie clip, dan graphic untuk memprogram objek serta animasi pendukung lainnya sesuai harapan.

\section{DAFTAR PUSTAKA}


Danar, K. 2010. Pintar Baca Tulis 1. Yogyakarta: Andi

Hasanudin \& Noviyanto, F. 2002. Pemrograman Action Script dengan Flash 5 dan Aplikasinya. Yogyakarta: Andi

Madiun, M. 2011. Aplikasi Web Databases dengan Dreamweaver dan Php-Mysql. Yogyakarta: Andi.
Setiawan, S. 2007. Membuat Aplikasi Flash secara Optimal. Yogyakarta: Andi

Wijanarto, J., Anthoinette, C., Rulli, K..2011. Mengenal Huruf ABC. Banten: Happy Holy Kids

Zainal F.A., Maulana, S.A. 2009. Membuat Mini Games dengan Flash. Yogyakarta: Andi 